\title{
Predicting Metal Temperature of Re- Heater Tubes of a typical Super Critical Utility Boiler using CFD Technique
}

\author{
Deepak Kumar Kanungo ${ }^{\# 1}$, Ravi Kiran $\mathrm{A}^{\# 2}$ Sachin Kumar Shrivastava ${ }^{\# 3}$ \\ ${ }^{\#}$ Centre of Excellence for CFD, BHEL Corporate R\&D, \\ Hyderabad-500093, India \\ ${ }^{1}$ kanungodk@bhel.in, ${ }^{2}$ ark.ravi@bhel.in, ${ }^{3}$ sachins@bhel.in
}

\begin{abstract}
Computational Fluid Dynamics (CFD) technique has been used to predict the metal temperature ofreheater $(\mathrm{RH})$ tubes in a typical supercritical utility boiler operating at design condition. The zone from Furnace Outlet Plane (FOP) till RH section in an upper furnace of super critical boiler has been modelled. CFD analyses are carried out using Conjugate Heat Transfer (CHT) method by capturing transfer of heat through metal walls, from flue gas to steam flowing inside selected RH tubes. The metal temperature of these selected RH tubes is predicted. Four cases have been studied covering 16 RH tube assemblies and the pattern of metal temperature distribution on selected RH tube walls is predicted. Three dimensional surfaces of wall temperature verses tube length for each of the RH tubes in 16 assemblies have been plotted which will help the designer in identifying likely zones of RH tube rupture at power plant sites. The average value of metal temperature in the $\mathrm{RH}$ tubes studied is $\mathbf{3 . 1 9 \%}$ higher than the design value of RH tube metal temperature for the concerned boiler. Commercial tools Gambit, IcemCfd and Ansys Fluent have been used for carrying out the CFD analyses and plotting tool Gnu Octave has been used to generate three dimensional surface plots.
\end{abstract}

Keyword:CFD, Reheater, Super critical, Flue gas, Metal temperature, Inlet header

\section{INTRODUCTION}

Fossil boilers, sometimes referred as steam generators, are typical heat exchangers which produce steam for power plant usage by burning coal inside. Saturated steam from water wall tubes of boiler enter the super heater (SH)and reheater (RH) tubes to get super-heated and reheated. Non-uniform distribution of hot flue gas outside $\mathrm{SH} / \mathrm{RH}$ tubes and steam inside $\mathrm{SH} / \mathrm{RH}$ tubes leads to development of metal temperature imbalance on tube walls which calls for higher safety margins for tube metals [1]. At power plant sites, high temperature erosion is the main reason for RH tube thinning and eventually tube rupture. Improper distribution of steam inside tubes plays a bigger role in tubes erosion than the improper distribution of gas outside tubes [2]. Hence monitoring the metal temperature of RH tube walls and taking preventive measures to avoid tube erosion is critical from a power plant's life point of view. Temperature sensors deployed at sites to measure the wall temperature of $\mathrm{SH} / \mathrm{RH}$ tubes do not provide a complete picture of all the $\mathrm{SH} / \mathrm{RH}$ tube wall's temperature. Traditionally, temperature distribution of flue gas outside tubes is predicted using CFD tools, without considering the steam flow inside tubes. This is done by assigning an estimated value of uniform temperature to $\mathrm{SH} / \mathrm{RH}$ tube walls, which are represented as thin plates. However, to obtain a complete picture of $\mathrm{RH}$ tube walls metal temperature distribution, CFD modelling of steam side is essential, using conjugate heat transfer method.

The flow of flue gas inside fossil boilers is simulated using commercially available CFD codes [3]-[7]. Many researchers have carried out CFD analysis of fossil boilers with the objectives varying from predicting combustion efficiency of furnace to the amount of pollutant formation from combustion. Chugen et al. [3], in their numerical study investigated the uneven wall temperature in cross-over pass and the formation of NOx using commercial CFD tool Fluent. The flow domain in the study of [3] extends up to the rear pass, including the RH and SH panels. But the RH and SH panels are represented either as constant temperature plates or porous zones, which is a common approximation for carrying out CFD analysis of boilers. Their study mainly focused on flow and temperature fields of flue gas, ignoring the steam side. Zhanjua et al. [4] have developed a numerical tool which integrates with CFD simulations to predict the slagging and fouling in coal-fired boilers. The focus of their study was to predict the ash deposition behaviour in furnace, hence here also the steam side phenomenon has been ignored. Krzysztof et al. [5] developed one 2-D model to predict the deposition of ash on superheater tubes of fossil boilers, without modelling the steam flow in tubes. 
Hari et al. [6] carried out a detailed CFD study on a 330 MW boiler using commercial CFD code Fluent, with the objective of identifying the likely zones of slagging and fouling. Hari et al. [6] also developed a threedimensional combustor model for a $610 \mathrm{MW}$ boiler using the same commercial CFD code Fluent, with the objective of determining the flow patterns of gas and coal particles and predicting the unevenness of temperature on super-heater and reheater panels. Most of the studies available in literature confine to the modelling of only flue gas side, primarily due to the extreme complexity involved in carrying out CFD simulations of steam flow inside SH and RH tubes. However, a few studies have been reported in literature which focus on steam flow phenomena, along with flow of flue gas.

Esmaeil et al. [2] carried out numerical investigation of an old $250 \mathrm{MW}$ rated fossil boiler to predict the effect of combustion and steam flow distribution on RH tubes erosion. They simulated combustion phenomena inside the boiler, studied steam mal-distribution of various types of headers like U-type and H-type headers and also simulated transfer of heat from combustion products to steam inside RH tubes. But as far as heat transfer to steam is concerned, they could simulate only three number of RH tubes, mainly owing to the complexity of modelling RH tubes. Schnell et al. [1] carried out detailed combustion and steam side simulations of fossil-fuel fired boilers using in-house solvers AILOS and DYNAMIC. The effect of operational conditions on the thermal performance of the boiler was thoroughly investigated by them. Various models like parallel tubes model, inlet \& outlet headers model, parallel steam lines model were investigated using DYNAMIC. But the boiler studied was a wall fired one having three layers of burners. The boiler considered in the present study is a cornered fired one. Mayur Kumar et al. [8] studied the flow and pressure distribution in header and tube assemblies and investigated the effect of design parameters like tube pitch, header diameter, tube diameter etc. But their study excludes the coupling of flow with temperature.

Simulating steam flow phenomena in fossil boilers through CFD is extremely complex and requires modelling of the complex geometry of SH/RH tubes. In the present work, a simplified methodology has been implemented for carrying out CFD simulation of steam flow inside RH tubes along with flue gas flowing outside tubes. The objective of the present work is to predict the metal temperature of RH tubes and to identify likely zones of hot spots on the RH tube walls. A curtailed portion of the upper furnace of a typical super critical boiler has been taken as the domain of interest. There are $50 \mathrm{RH}$ assemblies in the upper furnace of the concerned boiler and each RH assembly has 12 inlet tubes and 12 outlet tubes. Each inlet tube and outlet tube join each other at the midpoint to form a u-tube structure. Out of the $50 \mathrm{RH}$ tube assemblies, only $16 \mathrm{RH}$ assemblies are modelled as real tube assemblies and the remaining assemblies are treated as zero thickness plates with constant temperature assigned to them. Flue gas enters the CFD domain at the Furnace Outlet Plane (FOP) and exits through a vertical plane immediately after the RH section. Steam enters into each of the 16 modelled RH assemblies through 12 inlet RH tubes and exits through 12 outlet RH tubes (12 U-shaped tubes). Transfer of heat from flue gas to steam via metal wall is simulated by means of conjugate heat transfer method. Converged CFD simulation results predict the pattern of temperature distribution on the walls of each RH tube in the 16 modelled RH assemblies, which will help the designer to identify the likely zones of hot spots on RH tube walls.

\section{METHOD}

The CFD analysis is accomplished in two parts. In first part, the RH inlet header is simulated with steam as the only working fluid, to predict the amount of steam mass flow entering into each of the 50X12 RH tubes. In the second part, four case studies are performed covering sixteen RH tube assemblies in total, with the objective of finding out the temperature distribution on the metal walls of RH tubes. The domain of interest in the second part of simulation extends from FOP to a vertical plane, immediately after the rear RH panel, as depicted in Fig.1. Both, steam and flue gas are considered in this simulation, along with the metal wall. The mass flow of steam entering into each RH assembly, as predicted in first part of simulation is prescribed as the boundary condition for steam side in the second part of the simulation. The boundary condition for flue gas in the second part of the simulation is prescribed as a profile boundary condition, extracted from a previous CFD simulation of the same boiler with a specific burner tilt, carried out by [10]. Shrivastava[10] carried out CFD analysis of the complete supercritical boiler, with the objective of finding the exact impact of over-fired air on combustion performance. Like most of the studies available in literature, [10] also considered the SH and RH panels as constant temperature plates, without considering the steam side phenomena. Shrivastava[10] used k- $\varepsilon$ model as the turbulent model and Discrete Ordinate (DO) method for capturing radiative heat transfer. Shrivastava[10] considered species transport model to account for the coal combustion, along with eddy dissipation as turbulence chemistry interaction. 


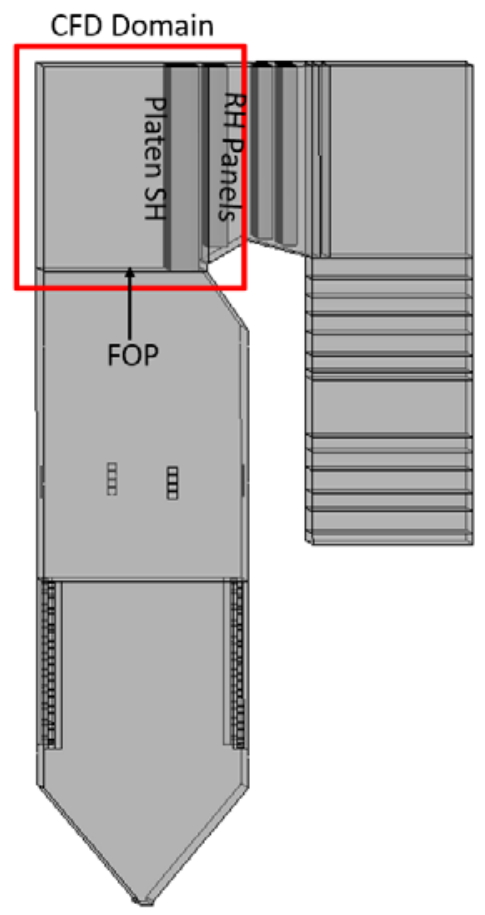

Fig.1: Schematic of $660 \mathrm{MW}$ furnace and the computational domain

As stated in introduction section, due to the extreme aspect ratio of RH tubes, only a curtailed portion of the furnace (Fig.1) with selected RH tube assemblies are considered in the CFD modelling. Four number of cases are formulated with four number of real RH tube assemblies (out of fifty assemblies) considered in each case, hence covering sixteen RH tube assemblies. In each case, other than the modelled RH tube assemblies, remaining $\mathrm{RH}$ assemblies are represented as zero thickness plates with a constant temperature assigned to them, as per design data available with the design team of Bharat Heavy Electricals Limited (BHEL). All the SH assemblies are also represented as zero thickness plates with constant temperature assigned to them (as per design data), which is different from the value assigned to RH section. The assignment of constant temperature to these RH and SH elements which are represented as zero thickness plates, effects a temperature drop in flue gas as it passes by the SH/RH zone. As depicted in Fig.1, in all the four case studies, the domain of interest for CFD analysis extends from Furnace Outlet Plane (FOP) to the rear RH panel. In each case, the flue gas domain extends from FOP to rear RH panel and the steam domain is constituted by the four vertically hanging RH tube assemblies. The flue gas and steam domain thermally interact with each other through the metal walls of RH tubes.

For creating solid model and generating mesh of the upper furnace and RH tube assemblies, commercial tools IcemCfd and Gambit are used. For carrying out CFD runs, Ansys Fluent 15.0 is used. Table-1 shows the complete list of RH assemblies considered for modelling in each of the four case studies; rest of the assemblies are represented as constant temperature plates in each case.

TABLEI. Details of RH Assemblies Considered For Modelling

\begin{tabular}{|c|c|}
\hline Case & $\begin{array}{c}\text { Serial number of RH assemblies modelled } \\
\text { (starting from right side of furnace) }\end{array}$ \\
\hline 1 & $1,13,37,50$ \\
\hline 2 & $2,14,26,38$ \\
\hline 3 & $10,22,34,46$ \\
\hline 4 & $3,15,27,39$ \\
\hline
\end{tabular}

\section{A. Solid model and meshing}

Solid model involves modelling of RH inlet header, modelling of RH tube assembly and modelling of the upper furnace enclosing SH and RH assemblies. Modelling of RH inlet header and RH tube assembly are done using pre- processing software IcemCfd. Hexahedral grids are generated on the RH assembly and the total mesh count for a single assembly is around 12.5 millions. The solid model of RH inlet header, a single RH tube assembly and the meshed domain of a portion of a single RH assembly is shown in Fig.2 through Fig.4. 


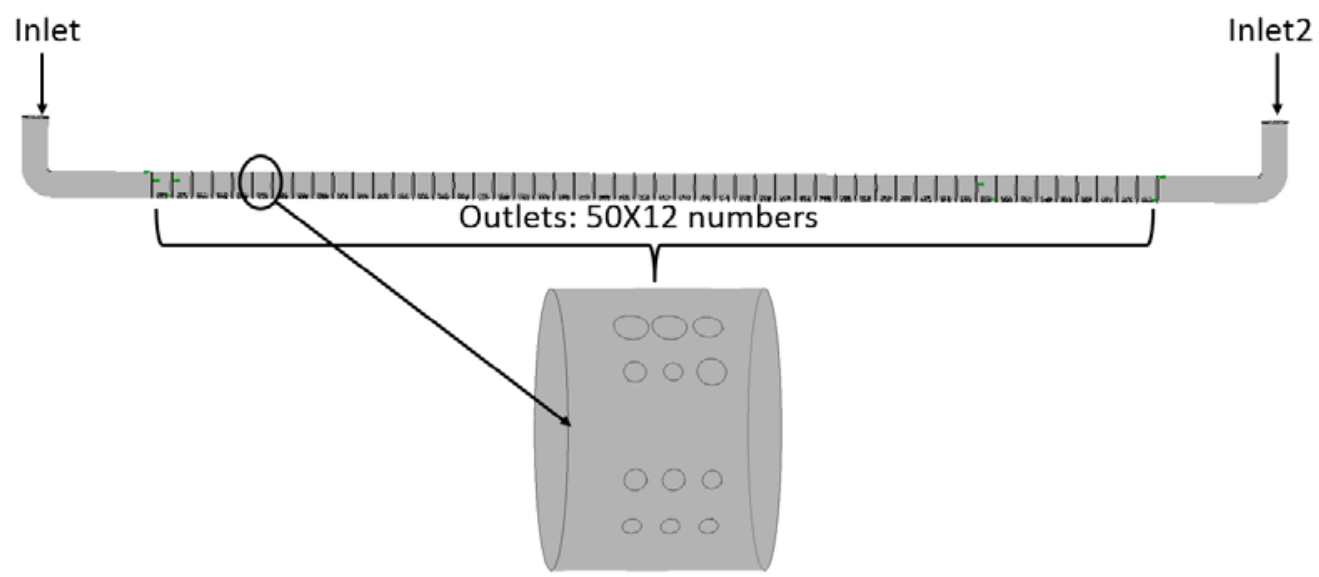

Fig.2: Solid model of RH inlet header; the magnified image is one single assembly

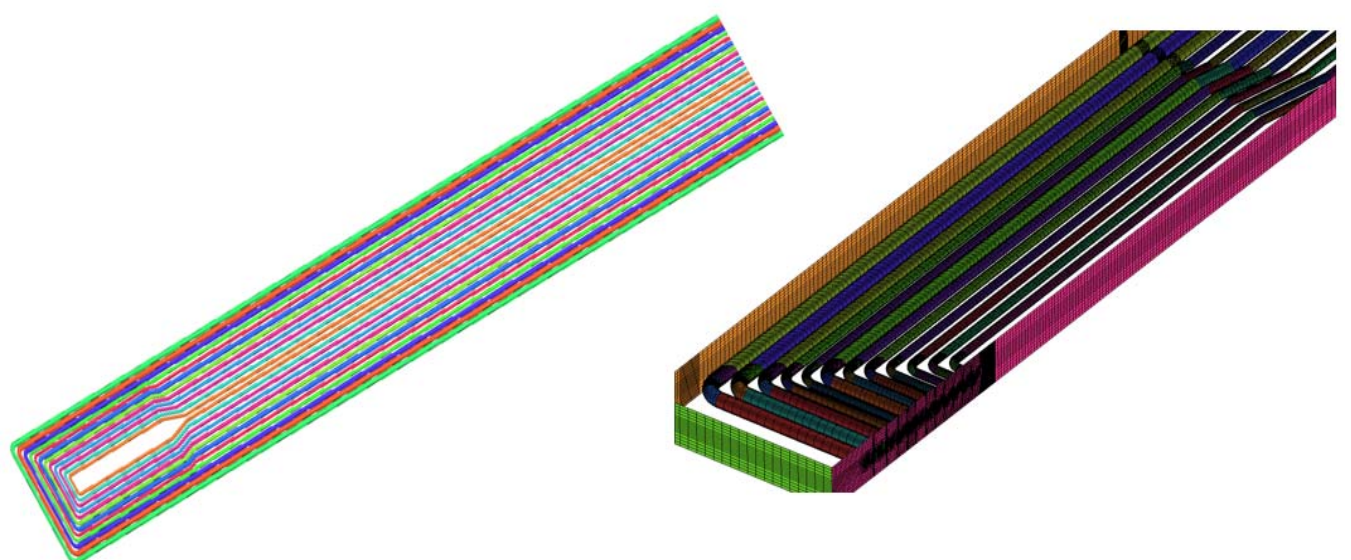

Fig.3: Solid model of single RH assembly and a magnified portion of the assembly
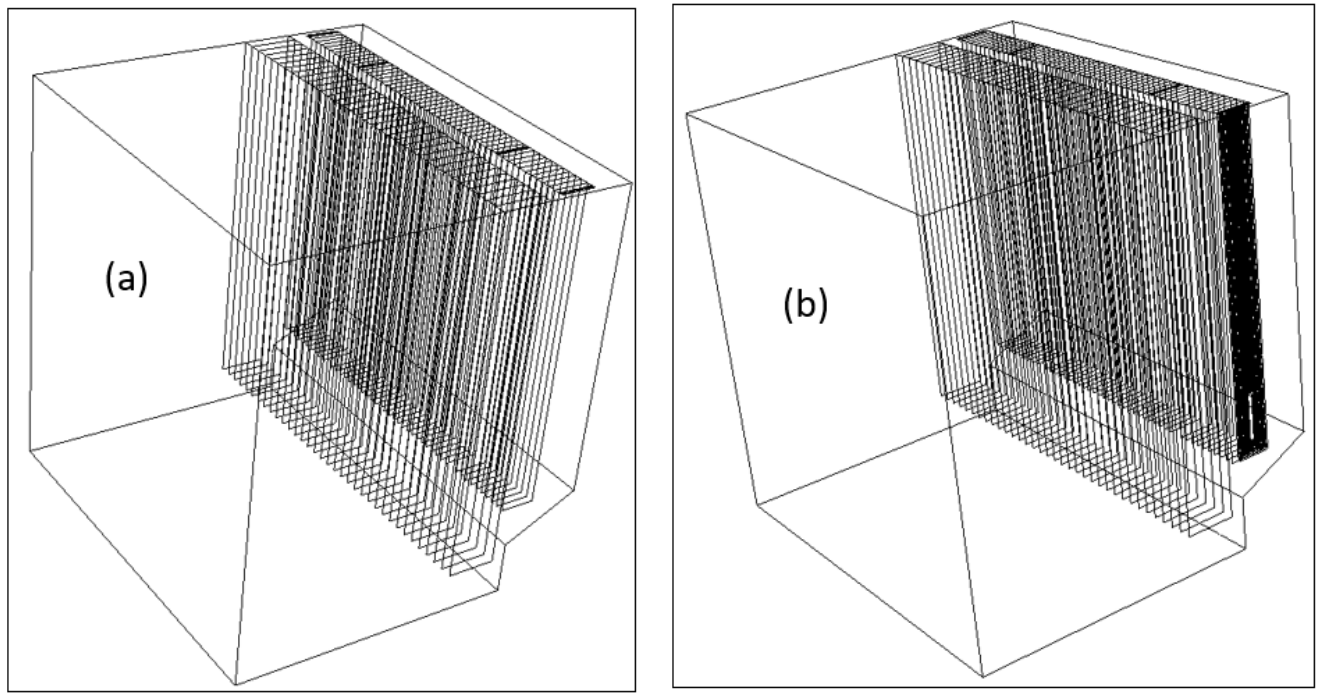

Fig.4: (a) RH section with zero thickness surface and (b) First RH assembly represented as real tube assemblies

Modeling of upper furnace enclosing SH and RH section is done using pre-processing software Gambit. A journal file is developed using Gambit to quickly accomplish the modeling and meshing of upper furnace for different cases. Separate mesh files of single RH assembly and upper furnace are stitched together in CFD solver AnsysFluent using the option "mesh interface" to establish connectivity. Fig.4 (a) and (b) show the upper furnace with zero thickness plates in RH section and upper furnace where one RH plate is replaced with real RH tube assembly, respectively. 


\section{B. Solver set up}

The CFD problem under consideration consists of two domains i.e. flue gas side and steam side. Flue gas enters the domain at FOP and exits after crossing rear RH panel. The boundary condition for flue gas is prescribed as a profile condition, which was extracted exactly at FOP, from previous CFD analysis of complete furnace by [10]. The velocity profile of flue gas at FOP consists of axial, tangential and radial velocity components, temperature component and turbulence parameters. Steam enters each RH assembly through 12 inlets and exits through 12 outlets (12 U-shaped tubes). Separate CFD analysis of RH inlet header is carried out to find out the mass distribution of steam entering to each RH assembly. This mass distribution of steam is used as mass flow boundary condition for steam in CFD analysis of upper furnace. The pressure and temperature of steam prevailing in $\mathrm{RH}$ section of this super-critical boiler is in the range of $50-55$ bar and $500-530^{\circ} \mathrm{C}$. Since the domain length is short in comparison with full furnace length and the extent of temperature variation of both flue gas and steam is not huge in RH section, all the flow and thermal properties of the materials in both the domains are kept constant during the simulations. This is a kind of approximation which aids in achieving better numerical convergence, without compromising on the accuracy of results. To account for conjugate heat transfer between the two fluid streams and the metal wall, the concept of "thin wall" by Fluent is employed. Initially, only flow equations are solved and after establishment of flow field of steam and flue gas, energy equation is solved. Turbulence model $k-\varepsilon$ is used for flow simulation and the model $k-\omega$ is used for energy simulations. Radiation effects are accounted for by using Discrete Ordinate (DO) model available in Ansys Fluent.

\section{Simulation}

Commercial CFD solver Ansys Fluent 15.0 is used to solve flow and energy equations in the domain. The CFD simulation is divided into two parts. In first part, the RH inlet header is simulated to find out the mass flow rate of steam entering into each of the 50X12 RH tubes hanging vertically downwards from the inlet header. In the second part, the upper furnace is simulated, capturing flow of flue gas, flow of steam inside selected RH tube assemblies and transfer of energy from flue gas to steam through metal walls. Multiple processors are employed in parallel to solve the CFD equations and numerical convergence is ensured to the extent of $10^{-3}$ for flow parameters and $10^{-6}$ for energy.

\section{RESULTS}

\section{A. $R H$ inlet header}

The average amount of steam mass flow entering into each of the RH tube assemblies is predicted and the normalized value of the same is plotted in Fig.5, normalization done with respect to the average value of temperature. Also, within each RH assembly the amount of steam entering into each of the $12 \mathrm{RH}$ tubes is predicted. A pool of data containing steam mass flow against each RH assembly and against each individual tube, is created. In the subsequent part of simulation, where tube assemblies are modeled along with the upper furnace, this mass flow rate is used as boundary condition at entrance of each tube. Fig. 6 shows the pathline of steam flow in the RH inlet header.

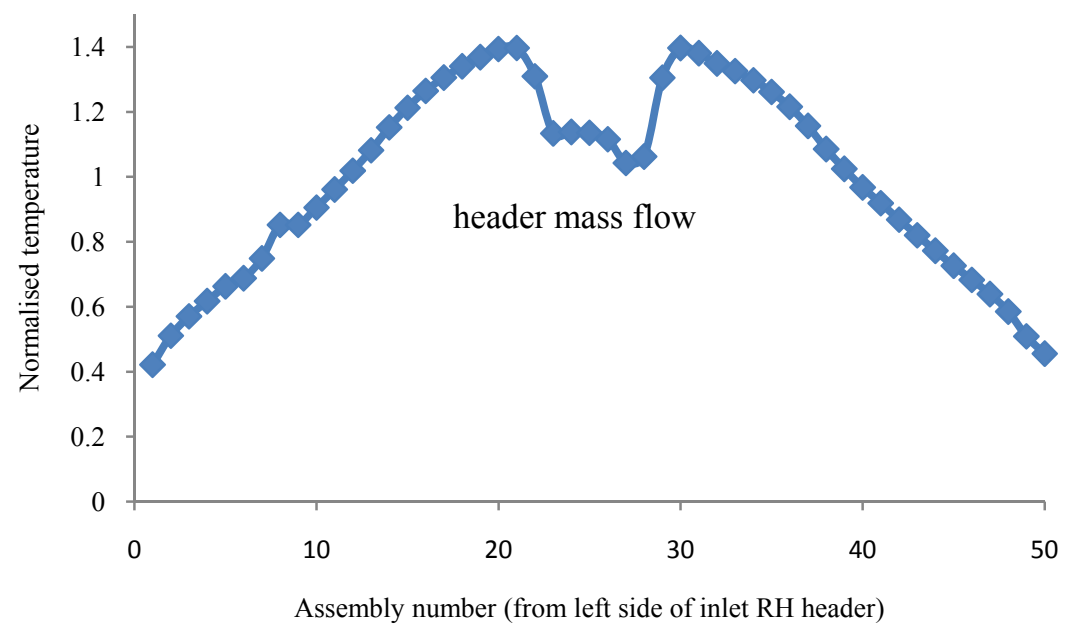

Fig.5: Steam mass flow distribution along the length of RH inlet header 


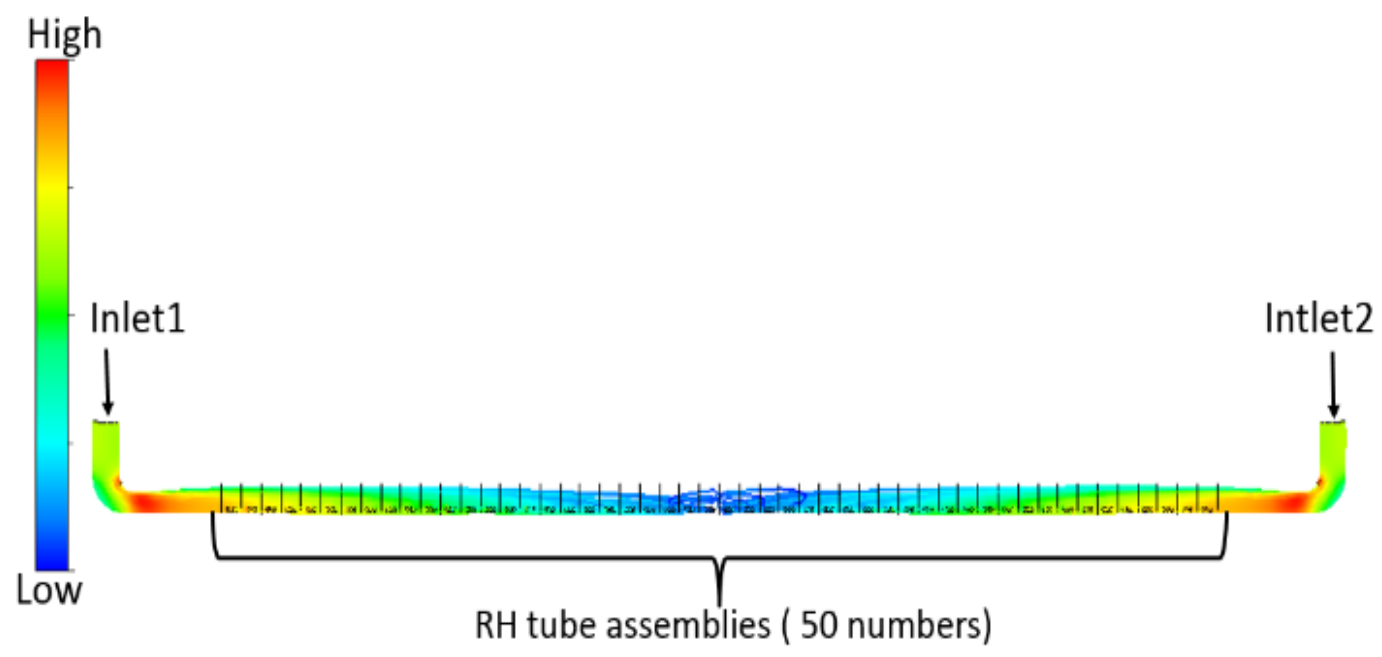

Fig.6: Pathlines of Steam flow in RH inlet header

\section{B. Upper furnace with four RH assemblies in each case}

Four number of case studies are performed, each case consisting of four number of RH tube assemblies. After getting convergence in the CFD simulation, the wall of each RH tube is split into either 18 or 20 parts along the length, depending on the length of the tube. On each part, average temperature value of metal wall is extracted and the temperature distribution along the length of each tube is plotted. The CFD predicted average metal temperature on all the tubes modelled by considering $16 \mathrm{RH}$ assemblies deviated from the design value by 3.19\%. Fig.7 through Fig.10show the variation of wall temperature along the length, for each of the 12 tubes in 4 of the $16 \mathrm{RH}$ assemblies modelled. The values on Y-axis are normalized values of temperature, normalization done with respect to the average value of temperature in the pool.

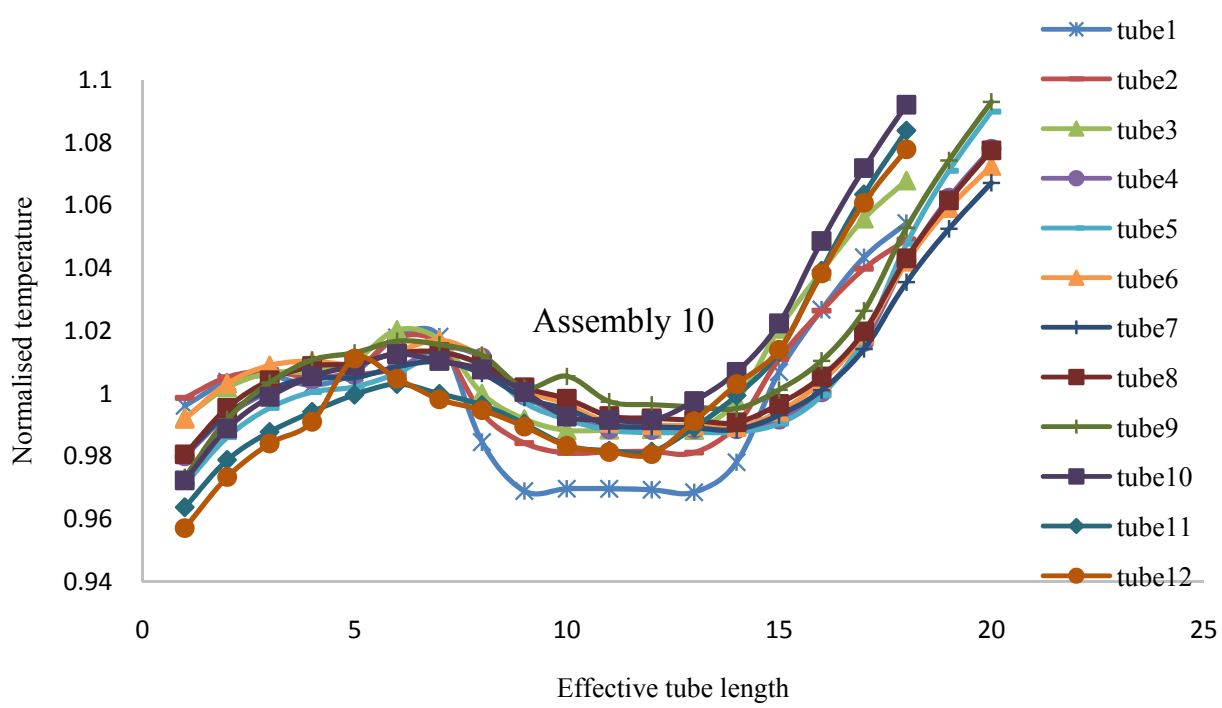

Fig.7: Variation of average wall temperature of $12 \mathrm{RH}$ tubes along the length, for assembly number 10 


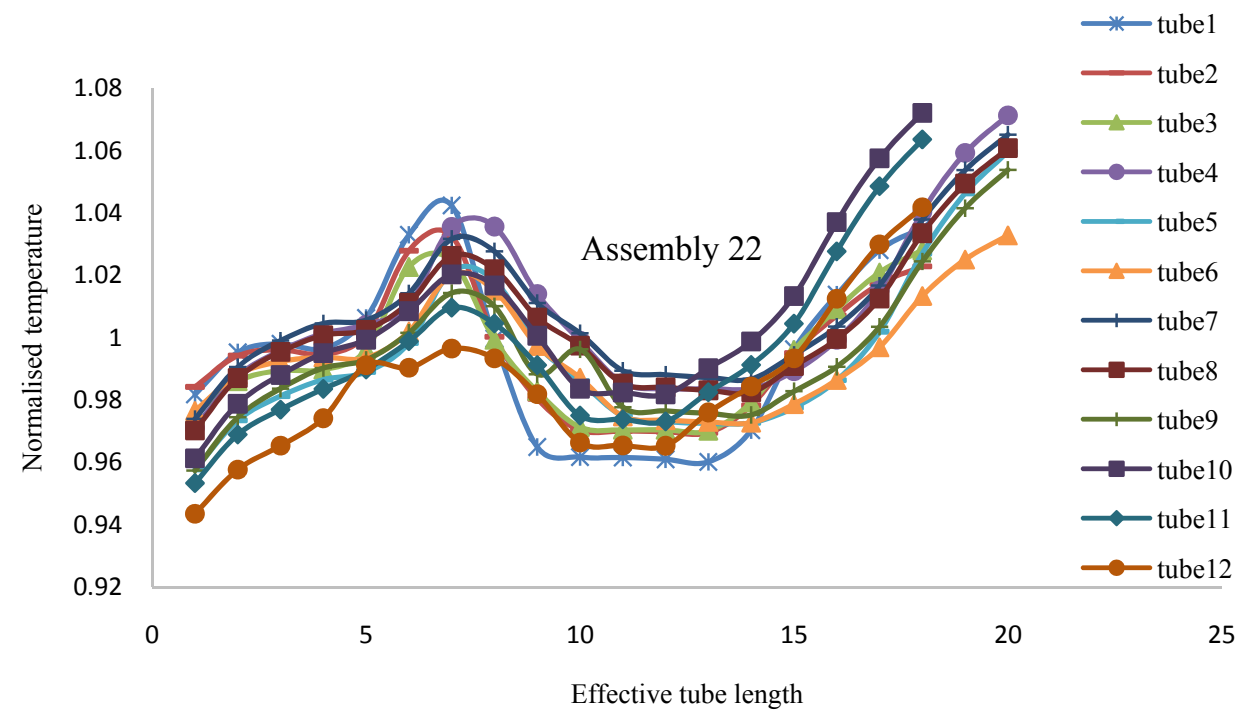

Fig.8: Variation of average wall temperature of $12 \mathrm{RH}$ tubes along the length, for assembly number 22

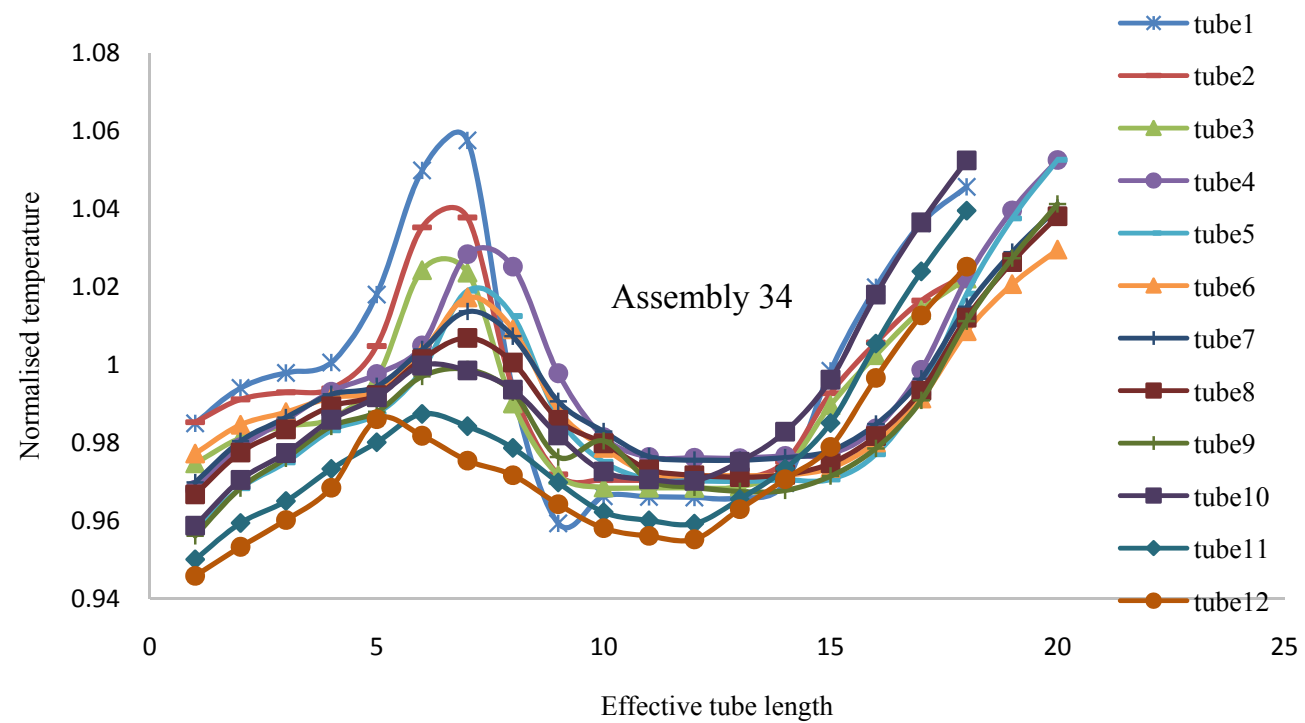

Fig.9: Variation of average wall temperature of $12 \mathrm{RH}$ tubes along the length, for assembly number 34 


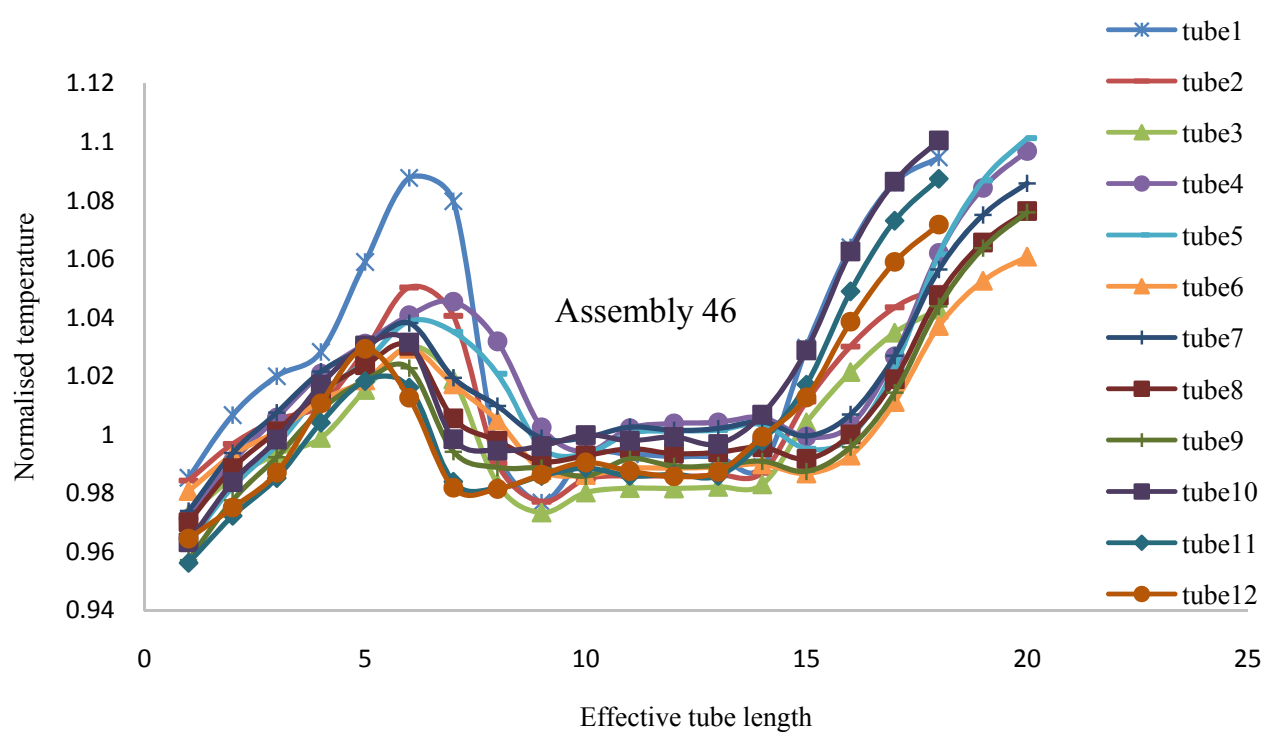

Fig.10: Variation of average wall temperature of $12 \mathrm{RH}$ tubes along the length, for assembly number 46

3-D surfaces are plotted using Gnu Octave to capture a complete picture of temperature distribution in RH section. The surface plots are represented in Fig.11 and Fig.12. The x-axis of the surface plots represents the tube length, the $\mathrm{y}$-axis represents the assembly number in $\mathrm{RH}$ section and $\mathrm{z}$-axis represents normalized temperature. For 12 RH tubes, 12 surface plots are produced in Fig.11 and Fig.12 to depict the temperature distributions in the entire RH section.
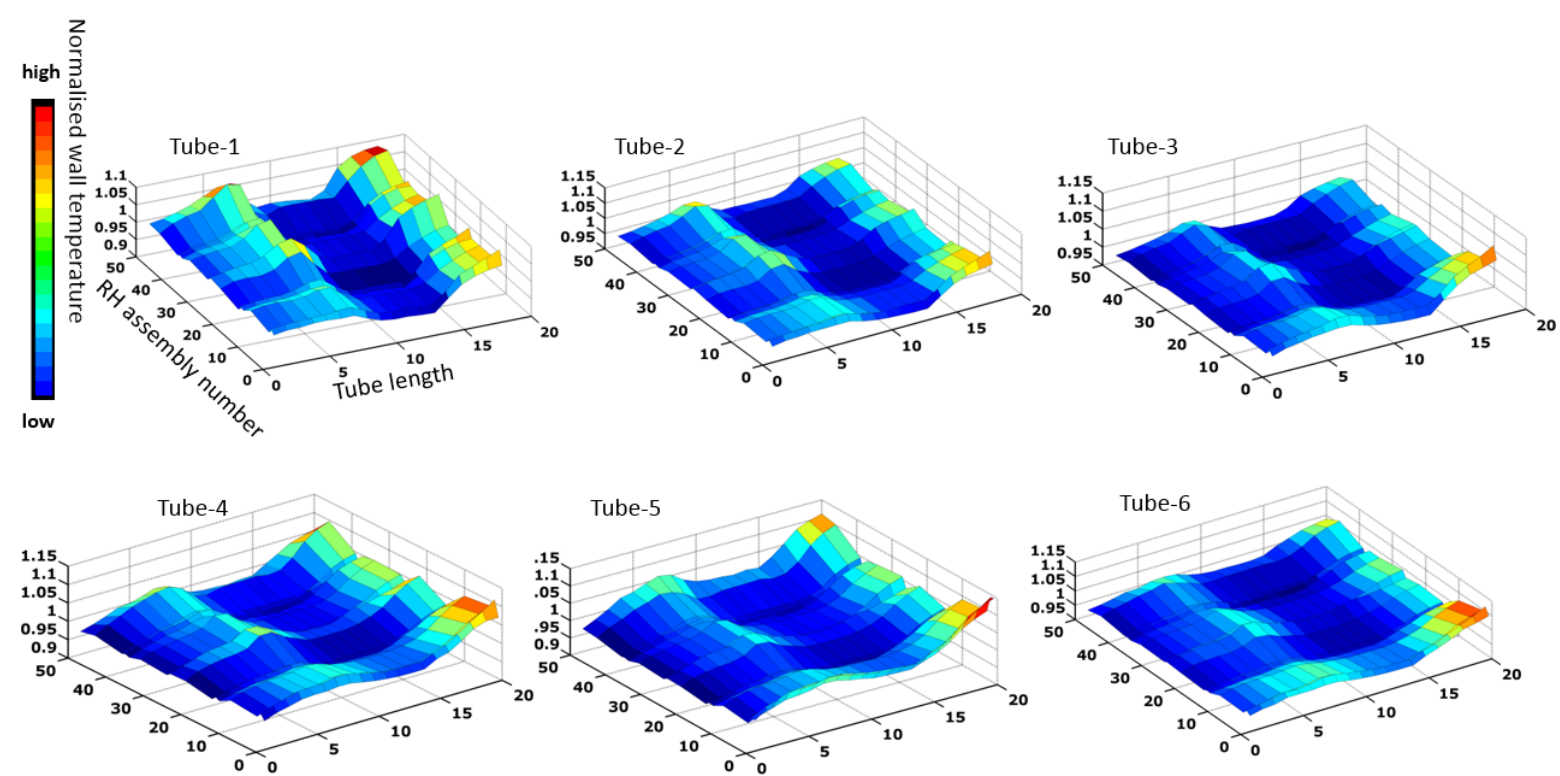

Fig.11: Wall temperature variation along tube length for RH tubes 1 to 6 in all sixteen assemblies modelled 

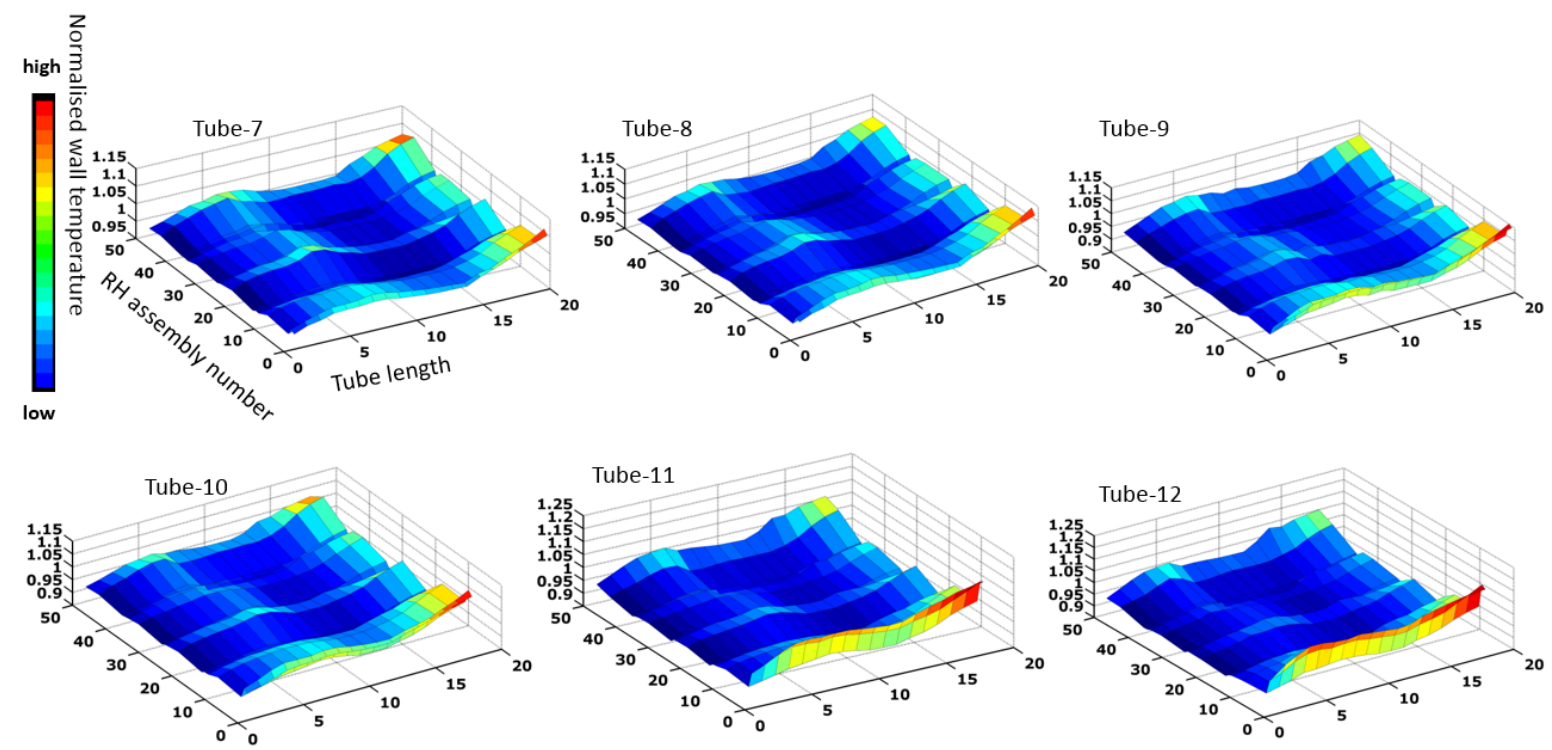

Fig.12: Wall temperature variation along tube length for RH tubes 7 to 12 in all sixteen assemblies modeled

Fig.13 shows the pathlines of flue gas and steam velocity in the curtailed portion of upper furnace, in one of the four cases studied. The domain shown in Fig. 13 consists of four number of RH assemblies, remaining RH assemblies and the entire SH section are modelled as thin plates with constant temperature. Flue gas enters from the horizontal face at the bottom of the upper furnace (FOP) and exits from the right vertical face of the upper furnace, essentially taking a right angled turn. Steam enters into each of the 12 tubes of four RH assemblies and exits from the remaining 12 tubes in the same four RH assemblies.

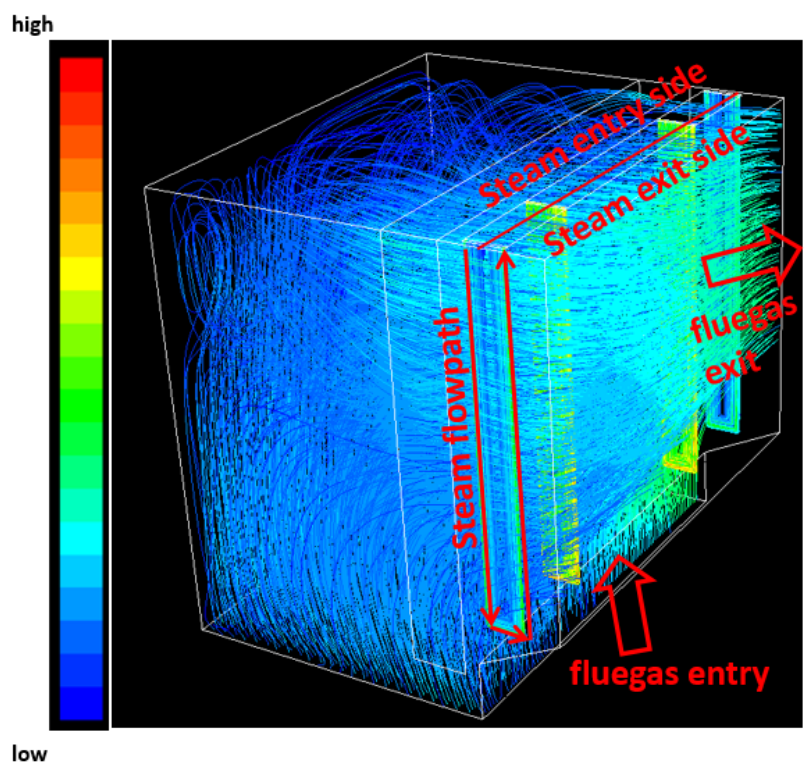

Fig.13: Pathlines of fluegas and steam velocity in upper furnace

Using post-processing tool of Ansys Fluent, four vertical planes are created, cutting all the modelled RH assemblies at mid-way. Contours of velocity and temperature for both flue gas and steam are plotted on these planes and the contour plots of velocity and temperature on one such plane is reported in Fig.14 and Fig.15, for one case. 

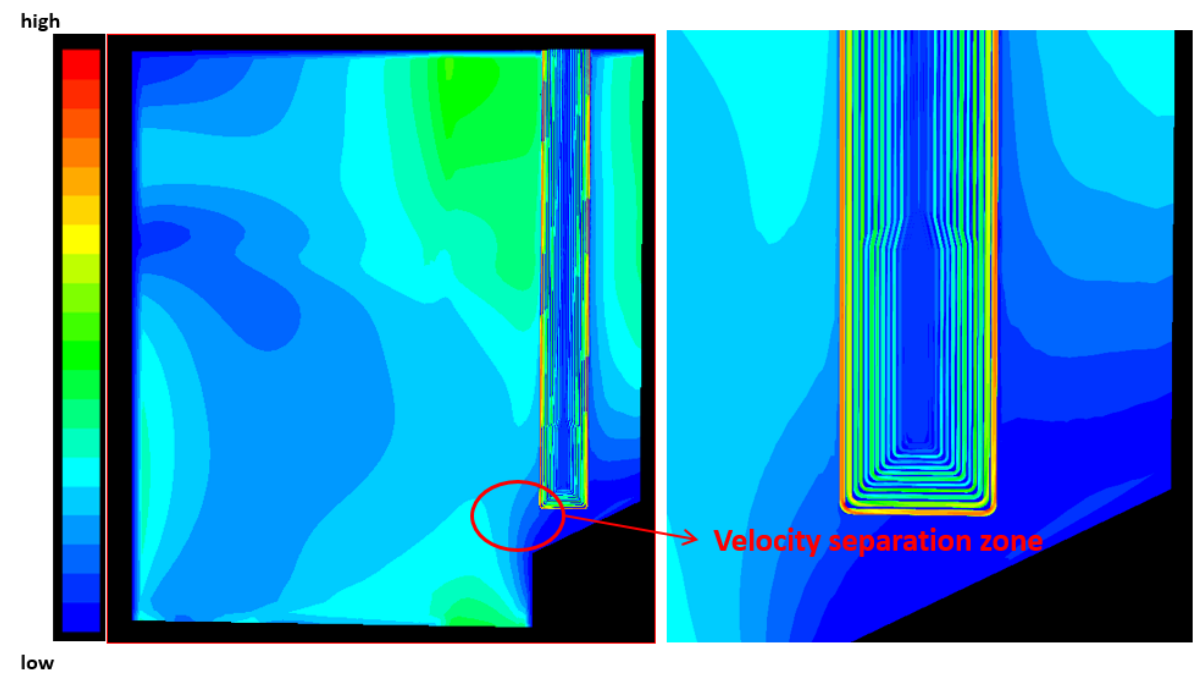

Fig.14: Contours of fluegas and steam velocity on a vertical plane
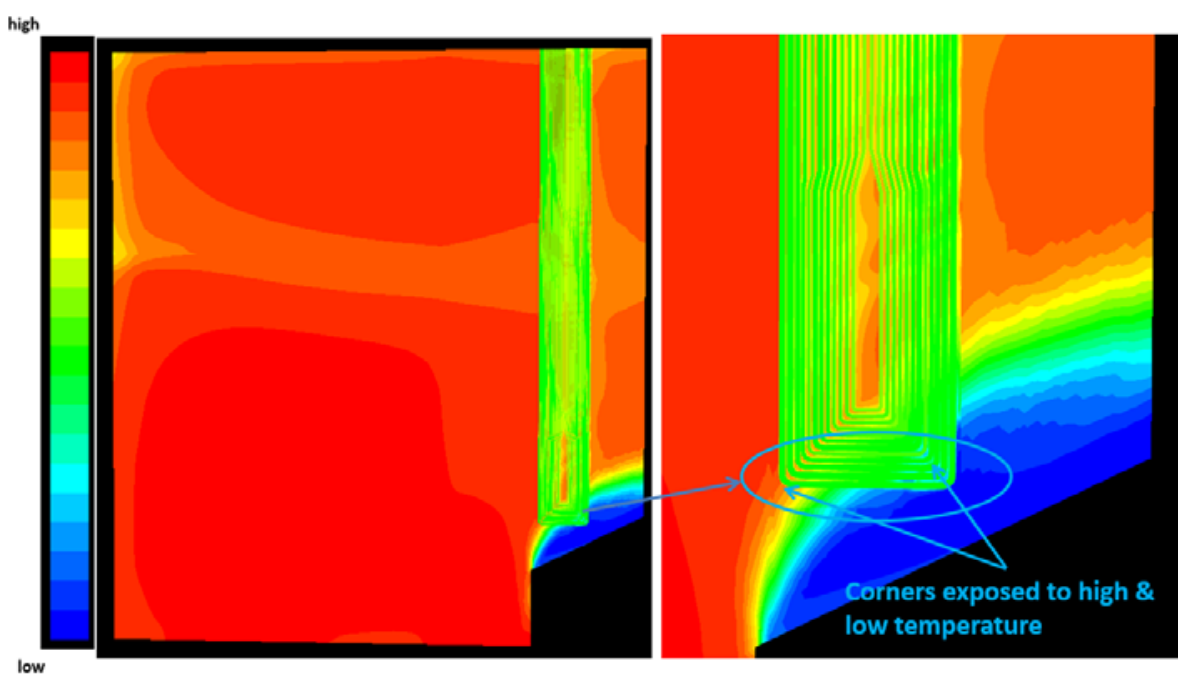

Fig.15: Contours of fluegas and steam temperature on a vertical plane

Using the post-processing tool of Ansys Fluent, horizontal planes are created in upper furnace, vertically cutting the RH tubes into two halves. On these planes, vectors of flue gas velocity are plotted and a section of one such plot is shown in Fig.16, for one of the four cases studied.

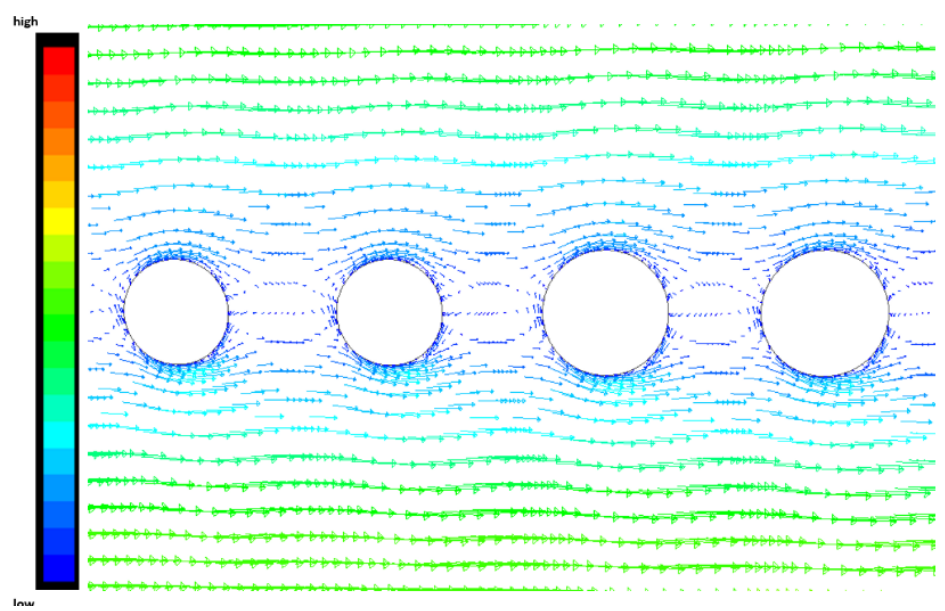

Fig.16: Vectors of fluegas velocity at a horizontal plane in upper furnace 


\section{Discussion}

\section{A. $R H$ inlet header}

As shown in Fig.5, the mass flow distribution of steam entering into each RH assembly follows a definite pattern along the length of RH inlet header. The amount of steam entering into each RH assembly increases as one moves away from both the inlets and just before the mid-point of inlet header, the mass flow value of both the streams achieve their respective peaks. Suddenly, at the mid-point of inlet header, the mass flow takes a dip just before both the inlet streams join each other, hence establishing a quite symmetric "bow-like" pattern. The predominant axial velocity of steam just at both the inlets prevents the steam from entering into the $\mathrm{RH}$ assemblies which are present near the inlets of header. But as both the streams collide with each other, due to directional change, the radial component of velocity becomes much more dominant and hence the $\mathrm{RH}$ assemblies which are present just before the mid-section of RH inlet header get more amount of steam flow. The establishment of the "bow-like" pattern of steam mass flow in RH inlet header, as depicted in Fig.5 is also corroborated in Fig.6, in terms of steam velocity pathlines. The "bow-like" like pattern of steam mass flow in $\mathrm{RH}$ inlet header is a validation of RH inlet header design for the specific boiler.

\section{B. Upper furnace with $4 \mathrm{RH}$ assemblies in each case}

Fig.7 through Fig.10 show the pattern of wall metal temperature of each tube in RH assembly number 10, 22, 34 and 46. The overall pattern of metal temperature distribution along the length of RH tube is same for all tubes in all the assemblies modelled, the absolute values being different from tube to tube. Along the length of each RH tube (U-shaped), the wall temperature increases from the top of the tube (where steam enters from the inlet header) to the first bent and decreases up to the second bent (along the horizontal section). Again from the second bent, the wall temperature increases up to the tube exit (re-joining outlet header). This particular pattern of wall metal temperature of RH tubes is greatly influenced by the distribution of flue gas temperature outside RH tubes. From Fig.14 and Fig.15, it can be observed that due the presence of a sharp corner, there is a velocity separation in flue gas side occurring below the RH tube assemblies when the flue gas takes the right turn. Due to this velocity separation, the two corners of each U-shaped RH tube are exposed to two significantly different temperature values of flue gas. This contributes to the sharp drop in temperature values of tube walls at the second bent. In Fig.7 through Fig.10, the first inflection point in the plots corresponds to the first bent of that particular RH tube and the second inflection point corresponds to the second bent of that RH tube. The portion of the plot joining both the inflection points corresponds to the horizontal section of that RH tube. Hence both the bents of all RH tubes are subject to the maximum thermal stress and are most likely to erode first.

In Fig. 11 and Fig.12, the wall metal temperature of each tube in all the 16 assemblies modelled is depicted as surface plots. The first RH tube in almost all the assemblies modelled is the hottest tube, having most number of hot spots. As discussed in the previous paragraph, the hot spots are predominantly near the first bent and the exit of the U-shaped RH tube. The inner most tube i.e. the 12th RH tube is the coolest tube with least number of hot spots on it. This may be due to the fact that surrounding outer tubes minimise the exposure of 12th tube to flue gas. The surface plots shown in Fig.11 and Fig.12 will serve the purpose of grossly identifying likely hot spot zones in the complete RH assembly. However, it is to be noted that only $16 \mathrm{RH}$ assemblies have been modelled out of $50 \mathrm{RH}$ assemblies. Interpolation/regression technique could have been employed to generate the data for in-between assemblies. But due to the haphazard nature of flue gas flow in upper furnace, interpolation/regression process may produce unrealistic information. Prediction of the metal temperature of RH tubes in the remaining assemblies constitute a significant portion of future work of this project.

Fig. 16 shows the velocity vectors of flue gas at a horizontal plane in upper furnace cutting across length of the first RH assembly at mid-way. The arrows on the contour plot are mostly unidirectional, indicating that there is no cross-flow of flue gas in-between two adjacent RH tube elements. This finding can be attributed to the fact that the gap in-between two adjacent RH tubes is very narrow in comparison to the height and the width of upper furnace. Traditionally, CFD analysis of upper furnace is carried out by assuming the RH and SH assemblies as zero thickness plates, which means the flow in-between two tube elements is neglected. The vector plot in Fig.16supports this assumption.

It is to be noted that since the boiler under consideration is yet to be operational, site operating data is not available for the boiler. Hence validating the detail pattern of temperature distribution on the tubes of $\mathrm{RH}$ assembly predicted by CFD analysis with site operating data is not feasible. However, the average temperature of metal walls of RH tubes predicted by this CFD analysis is compared with the design value of RH tubes for the specific boiler and the CFD predicted value of temperature is $3.19 \%$ higher than the design value. Additionally, the average values of flue gas temperature and velocity on various planes in upper furnace are also in good agreement with the design values of flue gas temperature and velocity in those respective sections. Also, the prediction of "bow like" pattern of steam mass flow distribution in RH inlet header is in agreement with design data. 


\section{Conclusion}

In this work, a methodology for predicting wall metal temperature of RH tubes in a typical super-critical utility boiler at design condition has been established using CFD technique. CFD simulations are carried out in two phases, first to find out the steam mass flow entering into each of the 50X12 RH tubes and then to find out the pattern of wall temperature of RH tubes. The distribution of steam mass flow entering into each of the 50 RH tube assemblies follows a symmetric "bow-like" pattern along the length of RH inlet header; the RH tube assemblies located around the central portion of header getting maximum steam flow. For predicting the metal temperature of RH tubes, four cases have been studied covering sixteen RH tube assemblies. In between two adjacent RH tube elements, there is no cross flow of flue gas. Within an RH assembly, along the length of each $\mathrm{RH}$ tube (U-shaped), the wall temperature increases from the top of the tube (where steam enters from inlet header) to the first bent, decreases up to the second bent (along the horizontal section) and then again increases up to the tube exit (re-joining outlet header). Both the bents of all RH tubes are subject to the maximum thermal stress and hence are most likely to erode first. This pattern is same for all RH tubes modelled. In each RH assembly, the hottest tube is the outer most tube and the coolest tube is the inner most one. The pattern of wall temperature distribution along the length of each RH tube modelled has been established and a standard surface plot for each such tube in the assembly has been created. This will help the designer in identifying the likely zones of RH tube rupture at power plant site, arising out of excessive tube heating. The average value of wall temperature of $\mathrm{RH}$ tubes predicted by CFD analysis is $3.19 \%$ higher than the design value.

\section{ACKNOWLEDGMENT}

The authors want to thank Professor Kirti Chandra Sahu, Department of Chemical Engineering, IIT Hyderabad for his guidance in descritizing the flow domain and ensuring numerical convergence of CFD runs. The authors acknowledge the support of BHEL management for encouraging to take up the specific project. The authors also thank the technical team of Ansys Inc. for the technical input provided. AnsysIcemCfd, Gambit and Ansys Fluent are the licensed products of Ansys Inc. for CFD applications.

\section{NOMENCLATURE}

$\begin{array}{ll}\text { RH } & \text { Reheater } \\ \text { SH } & \text { Superheater } \\ \text { CFD } & \text { Computational Fluid Dynamics } \\ \text { FOP } & \text { Furnace Outlet Plane } \\ \text { CHT } & \text { Conjugate Heat Transfer } \\ \text { DO } & \text { Discrete Ordinate } \\ \text { BHEL } & \text { Bharat Heavy Electricals Limited } \\ \text { IIT } & \text { Indian Institute of Technology }\end{array}$

\section{REFERENCES}

[1] Schnell, U., Dieter, H., Scheffknecht, G., Detailed combustion and steamside simulation of fossil-fuel fired utility boilers, Universität Stuttgart. Institute fürVerfahrenstechnik und Dampfkesselwesen, 2006

[2] Poursaeidi, E., Arabku, M., Using CFD to study combustion and steam flow distribution effects on reheater tubes operation, Journal of Fluid Engineering, Vol. 133, 051303:1-11, 2011

[3] Yin, C., Caillat, S., Harion, J., Baudoin, B., Perez, E., Investigation of flow, combustion, heat-transfer and emissions from a 609 MW utility tangentially fired pulverised-coal boiler, Fuel 81, 997-1006, 2002

[4] Zhanhua, M., Iman, F., Lu, P., Sears, R., Kong, L., Rokanuzzaman, A.,McCollor, D.P., Benson, S.A., A comprehensive slagging and fouling prediction tool for coal-fired boilers and its validation/application, Fuel Processing Technology 88, 1035-1043, 2007

[5] Wacławiak, K., Kalosz, S., A practical numerical approach for prediction of particulate fouling in PC boilers, Fuel 97, 38-48, 2012

[6] Vuthaluru, H.B., Kotadiya, N., Vuthaluru, R., French, D., CFD based identification of clinker formation regions in large scale utility boiler, Applied Thermal Engineering, Vol. 31, pages 1368-1380 382, 2011

[7] Vuthaluru, H.B., Vuthaluru, R., Control of ash related problems in a large scale tangentially fired boiler using CFD modelling, Applied Energy, Vol. 87, pages 1418-1426, 2010

[8] Gandhi, M.S., Ganguli, A.A., Joshi, J.B., Vijayan, P.K., CFD simulation for steam distribution in header and tube assemblies, Chemical engineering research and design 90, 487-506, 2012

[9] ANSYS Fluent Theory and User's Guide (Release 15.0, 2013)

[10] Shrivastava, Sachin A detailed technical report on studying the effect of the SOFA and yawing of air nozzles on performance of 660 MW supercritical furnace using CFD technique, BHEL Corporate Research and Development, Hyderabad, Unpublished results. 


\section{AUTHOR PROFILE}

Deepak Kumar Kanungo works as deputy Manager with BHEL Corporate R\&D, Hyderabad, India. He received his bachelor's degree in chemical engineering from Utkal University, Odisha and M.Tech in chemical engineering from IIT Kanpur. He has close to 10 years of experience in modeling and simulation of power plant equipment's using CFD tools. He has one patent and 5 copy right applications in his name. He is an incumbent doctoral research fellow at IIT Hyderabad.

Ravi Kiran A works as senior Engineer with BHEL Corporate R\&D, Hyderabad, India.He received his bachelor's degree in mechanical engineering from BITS Pilani. He has close to 8 years of experience in design and simulation of power plant equipments.

Sachin Kumar Shrivastava works assenior Manager withBHEL Corporate R\&D, Hyderabad, India.He received his M.Tech in chemical engineering from IIT Roorkee. He has close to 14 years of experience in modeling and simulation of coal combustion in fossil boilers. 